\title{
Fatores associados à soropositividade para Babesia, Toxoplasma, Neospora e Leishmania em cães atendidos em nove clínicas veterinárias do município de Lavras, MG
}

\author{
Factors associated the seropositivity for Babesia, Toxoplasma, Neospora e Leishmania in \\ dogs attended at nine veterinary clinics in the municipality of Lavras, MG \\ Antônio Marcos Guimarães*; Christiane M. B. M. Rocha; Trícia M. F. S. Oliveira; \\ Isabel R. Rosado; Letícia G. Morais; Raquel R. D. Santos
}

Departamento de Medicina Veterinária, Universidade Federal de Lavras - UFLA

Recebido em 22 de Novembro de 2007

Aceito em 2 de Junho de 2009

\section{Resumo}

O objetivo deste estudo foi determinar a frequência e avaliar a influência da idade, sexo e raça na soropositividade anti-Babesia canis, Toxoplasma gondii, Leishmania (L.) chagasi e Neospora caninum, por meio da reação de imunofluorescência indireta (RIFI), em amostras de soros coletadas de câes atendidos em nove clínicas veterinárias particulares do município de Lavras, MG, no período de agosto de 2000 a abril de 2002 . De 300 cáes, 73,3\% foram soropositivos (RIFI $\geq 1: 80)$ para $B$. canis, e houve um aumento significativo de reagentes $(\mathrm{p}<0,05)$ nos animais adultos se comparados com os jovens. Apenas um cão (0,3\%), proveniente do município de Belo Horizonte, apresentou anticorpos anti-L. (L.) chagasi (RIFI $\geq 1: 40$ ). Para T. gondii, de 218 cáes, 60,7\% foram positivos (RIFI $\geq 1: 16$ ). Em 228 amostras de soros, 3,1\% foram positivas (RIFI $\geq 1: 50$ ) para $N$. caninum. Infecçôes por B. canis e $T$. gondii são endêmicas em cáes atendidos em clínicas veterinárias particulares em Lavras. Não há evidências de casos autóctones de leishmaniose visceral canina em Lavras. Além disso, a infecção por $N$. caninum é pouco comum em cáes criados na zona urbana do município.

Palavras-chave: Protozoários, anticorpos, frequência, RIFI.

\begin{abstract}
The aim of the present study was to determine the frequency and evaluate the influence of age, sex and breed in seropositivity anti-Babesia canis, Toxoplasma gondii, Leishmania (L.) chagasi and Neospora caninum, by means of the indirect immunofluorescence antibody test (IFAT), in serum samples collected from dogs attended in nine private veterinary clinics in municipality of Lavras, Minas Gerais, Brazil, from August 2000 to April 2002. Of 300 dogs, 73.3\% were seropositive (IFAT $\geq 1: 80)$ to $B$. canis, and there was a significant increase $(\mathrm{p}<0.05)$ of the reagent in adult animals when compared with young. Only one $\operatorname{dog}(0.3 \%)$ from Belo Horizonte there was antibodies anti- $L$. (L.) chagasi (IFAT $\geq 1: 40$ ). T. gondii, of 218 dogs, $60.7 \%$ were positive (IFAT $\geq 1: 16$ ). In 228 serum samples, $3.1 \%$ were positive (IFAT $\geq 1: 50$ ) to $N$. caninum. Infections to $B$. canis and T. gondii occur as endemic form in dogs examined at private veterinary clinics in Lavras. There is no evidence that there are autochthonous cases of canine visceral leishmaniosis in Lavras. Besides this the infection by $N$. caninum is uncommon in dogs breed at the urbane zone of the municipality.
\end{abstract}

Keywords: Protozoan, antibodies, frequency, IFAT.

\section{Introdução}

Os cáes podem ser infectados naturalmente por uma grande variedade de protozoários que apresentam uma ampla distribuição geográfica. Além dos danos diretos causados aos animais, algumas espécies são zoonóticas, constituindo um sério problema de saúde pública.

\footnotetext{
*Autor para correspondência: Antônio Marcos Guimarães

Departamento de Medicina Veterinária, Universidade Federal de Lavras - UFLA, Campus Universitário, CP 3037, CEP 37200-000 Lavras - MG, Brasil e-mail: amg@ufla.br
}

Entre as protozooses que acometem os cães, babesiose canina é a de maior importância por ser uma enfermidade cosmopolita, causada por espécies do gênero Babesia, e mais frequente em regióes tropicais e subtropicais (BRANDÁO; HAGIWARA, 2002; GUIMARÁES et al., 2002; DANTAS-TORRES; FIGUEREDO, 2006).

No Brasil, o carrapato Rhipicephalus sanguineus atua como hospedeiro intermediário de Babesia canis vogeli que, recentemente, foi reconhecida como a subespécie que infecta os cães no país (PASSOS et al., 2005). 
Toxoplasma gondii e Neospora caninum são cosmopolitas, intimamente relacionados e responsáveis por distúrbios neurológico, gastrintestinal, respiratório e muscular em cães (MINEO et al., 2001). Felinos são considerados como hospedeiros definitivos de T. gondii (MARTINS; VIANA, 1998), e $N$. caninum tem como hospedeiros definitivos o cão (McALLISTER et al., 1998) e o coiote (GODIM et al., 2004).

A leishmaniose visceral americana (LVA) ou Calazar é uma zoonose descrita em diversas regióes no mundo. No Brasil, é causada pelo protozoário Leishmania (Leishmania) chagasi transmitida pela picada de Lutzomyia longipalpis. O cão é o principal reservatório em áreas urbanas, e o inquérito sorológico com a identificação e eutanásia de animais soropositivos, constitui uma das principais etapas no controle da LVA, pois os casos de Calazar canino precedem os casos em seres humanos em áreas urbanas do Brasil (SANTA ROSA; OLIVEIRA, 1997).

A ausência de informaçóes sobre a ocorrência de protozoários em cães criados em área urbana do município de Lavras, MG, motivou este estudo, que teve como objetivos determinar a frequência de anticorpos anti-B. canis, T. gondii, L. (L.) chagasi e $N$. caninum, por meio da reação de imunofluorescência indireta (RIFI), em cães atendidos em nove clínicas veterinárias particulares, e avaliar a associação da soropositividade com a idade, sexo e raça desses animais.

\section{Material e Métodos}

\section{1. Área de estudo}

O município de Lavras está localizado na bacia hidrográfica do Alto Rio Grande, na Regiāo Sul de Minas Gerais, com 918 m de altitude $\left(21^{\circ} 14 \mathrm{~S}\right.$ e $\left.45^{\circ} 00^{\prime}\right)$. A região possui clima do tipo CWA, segundo a classificação de KOPPEN, com duas estações bem definidas durante o ano. A estação chuvosa, geralmente começa em outubro e se estende até março, e o período seco compreendido entre os meses de abril a setembro. $\mathrm{Na}$ área urbana, o município apresenta 82.740 habitantes (IBGE, 2000), e a população canina estimada, na proporçáo de um cão para cada sete habitantes, é de 11.820 animais.

\section{Coleta de dados}

Amostras de sangue foram coletadas de 300 cães de ambos os sexos, com diferentes idades e raças, encaminhados a nove clínicas veterinárias particulares do município de Lavras, no período de agosto/2000 a abril/2002. A coleta foi feita uma única vez em cada animal, independentemente do que tenha motivado a consulta veterinária. Dados sobre idade, sexo e raça desses animais foram fornecidos pelos proprietários. O número de amostras coletadas foi baseado em uma prevalência esperada de $60 \%$, com um grau de confiança de $90 \%$ e uma margem de erro de $10 \%$ (CENTRO PAN-AMERICANO DE ZOONOSES, 1973). Nesse caso, deveriam ser coletadas 256 amostras, que foram aumentadas em $17 \%$ para efeito de segurança.

Essas amostras foram coletadas por punção da veia cefálica ou jugular em tubos de hemólise sem anticoagulante. Após a coagulação, as amostras foram centrifugadas a $500 \mathrm{G}$, por cinco minutos, e o soro foi separado, identificado individualmente e armazenado a $-20{ }^{\circ} \mathrm{C}$ até o momento de uso. Por causa da quantidade insuficiente de soro, o número de amostras que foram, posteriormente, submetidas à pesquisa de anticorpos anti-T. gondii ( $\mathrm{n}=218)$ e anti- $N$. caninum $(\mathrm{n}=228)$, ficou abaixo do número de amostras coletadas inicialmente $(\mathrm{n}=300)$.

\section{Sorologia}

A reação de imunofluorescência indireta (RIFI) foi utilizada para identificação de animais sororreagentes para B. canis, L. (L.) chagasi, T. gondii e $N$. caninum. Na sorologia para B. canis, T. gondii e $N$. caninum, a RIFI foi realizada conforme técnica descrita por Madruga et al. (2001). Para a pesquisa de $L$. (L.) chagasi, foi utilizada a técnica adotada pelo Centro de Pesquisas René Rachou (CPqRR /Fiocruz - MG). Na execução da RIFI, foi utilizado anticorpo anti-IgG de cáo marcado com isotiocianato de fluoresceína (FITC - Sigma F-7884), na diluição de 1:200. As lâminas foram observadas em microscópio de epifluorescência, com aumento de $400 x$.

O processamento das sorologias foi realizado no Laboratório de Doenças Parasitárias do Departamento de Medicina Veterinária da Universidade Federal de Lavras (DMV/UFLA), exceto para leishmaniose visceral canina, que foi executado no CPqRR/ Fiocruz - MG.

\section{Sorologia para Babesia canis}

Amostras de soro foram consideradas positivas com título de 1:80. As lâminas de antígeno utilizadas na RIFI foram produzidas no Laboratório de Doenças Parasitárias do DMV/UFLA, segundo metodologia descrita por Ribeiro et al. (1990).

\section{Sorologia para Toxoplasma gondii}

Utilizaram-se como antígeno taquizoítos de T. gondii, mantidos no Laboratório de Doenças Parasitárias do DMV/UFLA por sucessivas passagens em camundongos. Os soros foram considerados positivos, quando os taquizoítos de $T$. gondii apresentaram fluorescência periférica total na diluição 1:16.

\section{Sorologia para Neospora caninum}

Foram utilizados como antígeno taquizoítos de $N$. caninum, preparados por meio de multiplicação de taquizoítos de $N$. caninum (amostra Nc-1) em cultivos de células VERO, no Laboratório de Virologia do DMV/UFLA. Os soros positivos na diluição 1:50, consideradas reaçóes positivas (SILVA et al., 2007), foram submetidos a repetidas diluições para determinação do título final que ainda apresentava fluorescência periférica total dos taquizoítos de $N$. caninum.

\section{Sorologia para Leishmania (Leishmania) chagasi}

Formas promastigotas de $L$. (L.) chagasi foram utilizadas como antígeno, segundo metodologia utilizada no Laboratório de Leishmanioses (LL-CPqRR/Fiocruz - MG), e considerados positivos os soros com título de 1:40. 


\section{Análise estatística}

O teste do $\chi^{2}$ foi utilizado para testar a associação entre a soropositividade para as diferentes protozooses analisadas e as variáveis; sexo (macho, fêmea) e raça (definida, indefinida). O efeito da idade (em diferentes faixas etárias) foi avaliado pelo qui-quadrado de tendência. A razão de chances (OR) foi calculada para medir a magnitude da associação. Probabilidade menor que 0,05 foi considerada estatisticamente significativa.

\section{Resultados e Discussão}

Na Tabela 1, observa-se a distribuição por idade, sexo e raça dos 300 cáes atendidos nas clínicas veterinárias de Lavras, que foram submetidos a exames sorológicos.

Duzentas e vinte amostras $(73,3 \%)$ foram soropositivas para B. canis (Tabela 1). Essa frequência é bastante variável em cães de áreas urbanas, como pode ser observado em estudos efetuados em municípios como: Londrina, PR (36\%), São Paulo, SP (42,4\%), Belo Horizonte, MG (66,9\%) e Jaboticabal, SP (67\%) (RIBEIRO et al., 1990; DELL'PORTO et al., 1993; TRAPP et al., 2006; OLIVEIRA et al., 2008).

A frequência de cães positivos aumentou significativamente $(\mathrm{p}<0,05)$ nos animais adultos $(\geq 12$ meses de idade) se comparado com os jovens ( $<12$ meses de idade), demonstrando um risco crescente com o aumento da idade (Tabela 1). Esse fato também foi relatado por Ribeiro et al. (1990) e Trapp et al. (2006).

A ausência de associação ( $p>0,05)$ entre soropositividade e as variáveis sexo e raça (Tabela 1), demonstra que os animais, independentemente do sexo e da raça, tiveram oportunidades iguais para se infectarem com $B$. canis. Essa observação concorda com os achados de Ribeiro et al. (1990), Guimarães et al. (2002) e Trapp et al. (2006).
Cento e trinta e dois cães $(60,5 \%)$ apresentaram anticorpos anti-T. gondii. Estudos prévios demonstraram uma ampla variação na frequência de cães soropositivos em outras cidades, como: 19,7\% (SOUZA et al., 2003); 32,5\% (BRITO et al., 2002); 36,0\% (MINEO et al., 2001); 45,1\% (AZEVEDO et al., 2005); 46,1\% (DOMINGUES et al., 1998); 47,3\% (GUIMARÁES et al., 1992); e 91,0\% (GERMANO et al., 1985), respectivamente, em animais de áreas urbanas dos municípios de São Paulo, Botucatu, Jaboticabal, Campinas, em São Paulo; Uberlândia e Belo Horizonte, em Minas Gerais; Campina Grande, na Paraíba.

$\mathrm{O}$ número de cães sororreagentes foi maior $(\mathrm{p}<0,05) \mathrm{com}$ incremento da idade. A chance dos animais de 7 a 11 meses apresentarem anticorpos anti-T. gondii é 1,25 maior se comparada aos cães de zero a 6 meses de idade. Já dos animais de 37 a 72 meses de vida, a razão de chances (odds ratio) é sete vezes maior (Tabela 2 ). Esse resultado concorda com os descritos previamente por outros autores, que também observaram maior frequência de reagentes em cães mais velhos (GUIMARÁES et al., 1992; BRITO et al., 2002; AZEVEDO et al., 2005). Essa diferença tem sido atribuída ao aumento da probabilidade de exposição ao $T$. gondii com o aumento da idade do animal (Tabela 2).

Não houve diferença significativa $(p>0,05)$ entre a proporção de animais positivos de acordo com o sexo e a raça (Tabela 2). Outros estudos também não observaram associação da infecção com sexo (GERMANO et al., 1985; CABRAL et al., 1998; ALI et al., 2003; CÂNON-FRANCO et al., 2004; AZEVEDO et al., 2005), estando coerentes com o mecanismo de infecção fecal-oral de $T$. gondii (contato com solo, alimentos ou água contaminados com oocistos esporulados), demonstrando que machos e fêmeas possuem as mesmas probabilidades de se infectarem com este coccídeo.

Em relação à raça, os resultados deste estudo estáo de acordo com os de Brito et al. (2002). Isso pode ser explicado, em parte, pelo

Tabela 1. Soropositividade anti-Babesia canis em 300 cães atendidos em nove clínicas veterinárias particulares do município de Lavras, MG, no período de agosto de 2000 a abril de 2002 .

\begin{tabular}{|c|c|c|c|c|}
\hline \multirow{2}{*}{ Variáveis independentes } & \multicolumn{2}{|c|}{ Número de cáes } & \multirow{2}{*}{ Valor de $p$} & \multirow{2}{*}{$\begin{array}{l}\text { Odds ratio }(\mathrm{OR}) \\
\quad \text { (tendência) }\end{array}$} \\
\hline & Examinados & Positivos (\%) & & \\
\hline \multicolumn{5}{|l|}{ Idade (meses) } \\
\hline $0-6$ & 38 & $24(63,1)$ & $0,02^{1}$ & 1,00 \\
\hline $7-11$ & 46 & $30(65,2)$ & - & 1,09 \\
\hline $12-24$ & 83 & $61(73,5)$ & - & 1,62 \\
\hline $25-36$ & 42 & $33(78,6)$ & - & 2,14 \\
\hline $37-72$ & 31 & $25(80,6)$ & - & 2,43 \\
\hline$>72$ & 36 & $29(80,5)$ & - & 2,42 \\
\hline Indeterminada $^{3}$ & 24 & $18(75,0)$ & - & - \\
\hline \multicolumn{5}{|l|}{ Sexo } \\
\hline Macho & 144 & $103(71,5)$ & $0,50^{2}$ & - \\
\hline Fêmea & 152 & $114(75,0)$ & - & - \\
\hline Indeterminado $^{3}$ & 4 & $3(75,0)$ & - & - \\
\hline \multicolumn{5}{|l|}{ Raça } \\
\hline Definida & 201 & $145(72,1)$ & $0,54^{2}$ & - \\
\hline Indefinida & 94 & $71(75,5)$ & - & - \\
\hline Indeterminada ${ }^{3}$ & 5 & $4(80,0)$ & - & - \\
\hline
\end{tabular}

${ }^{1}$ Qui-quadrado de tendência; ${ }^{2}$ qui-quadrado; e ${ }^{3}$ não foi informado(a) na ficha individual do animal. 
Tabela 2. Soropositividade anti-Toxoplasma gondii em 218 cães atendidos em nove clínicas veterinárias particulares do município de Lavras, MG, no período de agosto de 2000 a abril de 2002.

\begin{tabular}{|c|c|c|c|c|}
\hline \multirow{2}{*}{ Variáveis independentes } & \multicolumn{2}{|c|}{ Número de cães } & \multirow{2}{*}{ Valor de $\mathrm{p}$} & \multirow{2}{*}{$\begin{array}{c}\text { Odds ratio }(\mathrm{OR}) \\
\text { (tendência) }\end{array}$} \\
\hline & Examinados & Positivos (\%) & & \\
\hline \multicolumn{5}{|l|}{ Idade (meses) } \\
\hline $0-6$ & 38 & $16(42,1)$ & $0,00^{1}$ & 1,00 \\
\hline $7-11$ & 31 & $15(48,4)$ & - & 1,29 \\
\hline $12-24$ & 60 & $33(55,0)$ & - & 1,68 \\
\hline $25-36$ & 28 & $22(78,6)$ & - & 5,04 \\
\hline $37-72$ & 25 & $21(84,0)$ & - & 7,22 \\
\hline$>72$ & 36 & $27(75,0)$ & - & 4,13 \\
\hline \multicolumn{5}{|l|}{ Sexo } \\
\hline Macho & 104 & $63(60,6)$ & $0,055^{2}$ & - \\
\hline Fêmea & 114 & $83(72,8)$ & - & - \\
\hline \multicolumn{5}{|l|}{ Raça } \\
\hline Definida & 142 & $80(56,3)$ & $0,08^{2}$ & - \\
\hline Indefinida & 76 & $52(68,4)$ & - & - \\
\hline
\end{tabular}

${ }^{1}$ Qui-quadrado de tendência; e ${ }^{2}$ qui-quadrado.

estilo de vida e hábitos alimentares dos cães envolvidos no presente estudo que, aparentemente, estariam igualmente expostos à infecção por T. gondii. Esses animais, por serem sem raça definida, podem indicar um menor cuidado por parte de seus proprietários, que, provavelmente, investiram pouco ou nenhum recurso financeiro para sua aquisição. Apesar disso, eram tratados como se fossem cães de raça definida. Dispunham de assistência veterinária e, provavelmente, acesso restrito à rua, já que o livre acesso representa fator de risco para infecção com T. gondii, conforme relatado por Ali et al. (2003) e Cânon-Franco et al. (2004).

Sete amostras $(3,1 \%)$ foram soropositivas para $N$. caninum, consistindo de um macho $(14,3 \%)$ e seis fêmeas $(85,7 \%)$ e faixa etária entre 17 meses a dez anos de idade. A baixa frequência de anticorpos anti- $N$. caninum pode ser explicada, em parte, pelo estilo de vida e hábitos alimentares desses cães que viviam na área urbana de Lavras. A população estudada era constituída de animais com assistência veterinária, criados em área urbana e, desse modo, estavam menos expostos à infecção por $N$. caninum. Provavelmente, eram alimentados com raçáo comercial ou alimentos caseiros cozidos e, consequentemente, com baixo risco de ingerir alimento de origem bovina (feto abortado, placenta e fluidos biológicos) ou pequenos mamíferos infectados com $N$. caninum, que constituem uma das principais fontes de infecção deste protozoário para cães mantidos em áreas rurais (DUBEY, 2003).

A frequência de animais positivos para $N$. caninum em Lavras, MG, ficou bem abaixo dos valores de 10,0, 8,3, 10,7, 8,4 e $26,5 \%$ observados em cães criados em áreas urbanas de municípios como São Paulo, SP (GENNARI et al., 2002), Monte Negro, RO (CÂNON-FRANCO et al., 2004), Uberlândia, MG (FERNANDES et al., 2004), Campina Grande, PB (AZEVEDO et al., 2005) e Campo Grande, MS (ANDREOTTI et al., 2006), respectivamente. Porém foi similar ao resultado de $3,7 \%$ relatado por Mineo et al. (2001), quando testaram 163 cães com distúrbios neuromuscular, respiratório e/ou gastrintestinal examinados no Hospital Veterinário da Universidade Federal de Uberlândia, MG. Valores de soroprevalência em cáes variando de 0,2 a 29,0\% foram reportados por Dubey (1999). Essa ampla variação de resultados, incluindo o observado em Lavras, MG, pode ser explicada pelos diferentes ensaios sorológicos utilizados, pelo ponto de corte (cut off) adotado, pela população amostrada e pelo tipo de amostragem.

Neste estudo, as frequências do título final dos soropositivos ao $N$. caninum foram: 1:50 (1/7); 1:100 (2/7); 1:400 (1/7); $1: 800(1 / 7) ; 1: 3200(1 / 7)$; e 1:6400 (1/7). Observa-se que três dos sete cães soropositivos para $N$. caninum tiveram título $>800$. Essa observação, segundo Barber e Trees (1996), é sugestiva de doença clínica, embora, no presente estudo, todos os animais sororreagentes estavam, aparentemente, normais.

Em relação à $L$. (L.) chagasi, apenas um animal $(0,3 \%)$ apresentou anticorpos específicos na diluição $1: 40$. Na época, a proprietária foi comunicada e relatou que o cão tinha sido adquirido em Belo Horizonte e transferido para Lavras com um ano de idade. Com 19 meses de idade, o animal foi submetido à eutanásia em uma clínica veterinária particular de Lavras, já apresentando sinais clínicos da doença. Esse fato configura um caso alóctone proveniente de Belo Horizonte, município que apresentava uma prevalência de $64,6 \%$ de cães soropositivos para $L$. (L.) chagasi, na região metropolitana, segundo Silva et al. (2001).

É importante ressaltar que, embora, no presente trabalho, tenha sido observado uma alta frequência de cães soropositivos para B. canis (67\%), não foi detectado nenhum cão do município de Lavras infectado por $L$. (L.) chagasi, demonstrando que não ocorreu reação cruzada entre estes hemoparasitas, resultado que concorda com o estudo realizado por Oliveira et al. (2008).

\section{Conclusóes}

Em Lavras (MG), infecçóes por B. canis e $T$. gondii são endêmicas em cães atendidos em clínicas veterinárias particulares, com uma maior taxa de animais adultos soropositivos; a infecção por $N$. caninum é incomum em animais criados na área urbana e náo há evidências de casos autóctones para leishmaniose visceral canina no município. 


\section{Agradecimentos}

Os autores agradecem aos clínicos veterinários da cidade de Lavras, por possibilitarem a realização deste estudo.

\section{Referências}

ALI, C. N. et al. Seroepidemiology of Toxoplasma gondii in dogs in Trinidad and Tobago. Veterinary Parasitology, v. 113, n. 3/4, p. 179-187, 2003.

ANDREOTTI, R. et al. Occurrence of Neospora caninum in dogs and its correlation with visceral leishmaniasis in the urban area of Campo Grande, Mato Grosso do Sul, Brazil. Veterinary Parasitology, v. 135, n. 3/4, p. 375-379, 2006.

AZEVEDO, S. S. et al. Seroepidemiology of Toxoplasma gondii and Neospora caninum in dogs from the state of Paraíba, Northeast region of Brazil. Research in Veterinary Science, v. 79, n. 1, p. 51-56, 2005.

BARBER, J. S.; TREES, A. J. Clinical aspects of 27 cases of neosporosis in dogs. Veterinary Record, v. 139, n. 18, p. 439-443, 1996.

BRANDÃO, L. P.; HAGIWARA, M. K. Babesiose canina: revisão. Clínica Veterinária, ano 8, n. 41, p. 50-59, 2002.

BRITO, A. F. et al. Epidemiological and serological aspects in canine toxoplasmosis in animals with nervous symptoms. Memórias do Instituto Oswaldo Cruz, v. 97, n. 1, p. 31-35, 2002.

CABRAL, D. D. et al. Frequency of anti-Toxoplasma gondii antibodies in apparently healthy dogs of the city of Uberlândia - MG. Revista Brasileira de Parasitologia Veterinária, v. 7, n. 2, p. 87-90, 1998.

CANÓN-FRANCO, W. A. et al. Occurrence of anti-Toxoplasma gondii antibodies in dogs in the urban area of Monte Negro, Rondônia, Brazil. Veterinary Research Communication, v. 28, n. 2, p. 113-118, 2004.

CENTRO PAN-AMERICANO DE ZOONOSES - CEPANZO. Procedimientos para estudios de prevalencia de enfermidades cronicas en el Ganado. Buenos Aires: CEPANZO, 1973. 35 p.(nota técnica n. 18).

DANTAS-TORRES, F.; FIGUEREDO, L. A. Canine babesiosis: a Brazilian perspective. Veterinary Parasitology, v. 141, n. 3/4, p. 197-203, 2006.

DELL'PORTO, A.; OLIVEIRA, M. R.; MIGUEL, O. Babesia canis in stray dogs from the city of São Paulo: comparative studies between the clinical and hematological aspects and the indirect fluorescence antibody test. Revista Brasileira Parasitologia Veterinária, v. 2, n. 1, p. 37-40, 1993.

DOMINGUES, L. M. et al. Canine toxoplasmosis: a comparative evaluation of the detection of anti-Toxoplasma gondii antibodies by the indirect immunoenzymatic assay (ELISA) and the indirect immunofluorescence reaction (IIF). Revista Brasileira de Parasitologia Veterinária, v. 7, n. 2, p. 79-85, 1998.

DUBEY, J. P. Recent advances in Neospora and neosporosis. Veterinary Parasitology, v. 84, n. 3/4, p. 349-367, 1999.

DUBEY, J. P. Review of Neospora caninum and neosporosis in animals. Korean Journal of Parasitology, v. 41, n. 1, p. 1-16, 2003.

FERNANDES, B. C. T. M. et al. Prevalence of anti-Neospora caninum antibodies in dogs from urban, periurban and rural areas of the city of Uberlândia, Minas Gerais, Brazil. Veterinary Parasitology, v. 123, n. $1 / 2$, p. $33-40,2004$.
GENNARI, S. M. et al. Occurrence of Neospora caninum antibodies in sera from dogs of the city of São Paulo, Brazil. Veterinary Parasitology, v. 106, n. 2, p. 177-179, 2002.

GERMANO, P. M. L., ERBOLATO, E. B., ISHIZUKA, M. M. Estudo sorológico da toxoplasmose canina, pela prova de imunofluorescência indireta, na cidade de Campinas, 1981. Revista da Faculdade de Medicina Veterinária e Zootecnia da Universidade de Sáo Paulo, v. 22 , n. 1 , p. $53-58,1985$.

GODIM, L. F. P. et al. Coyotes (Canis latrans) are definitive hosts of Neospora caninum. International Journal for Parasitology, v. 34, n. 2, p. 159-161, 2004.

GUIMARÃES, A. M. et al. Freqüência de anticorpos anti-Toxoplasma gondii em cães de Belo Horizonte, Minas Gerais. Arquivo Brasileiro de Medicina Veterinária e Zootecnia, v. 44, n. 1, p. 67-68, 1992.

GUIMARĀES, A. M.; OLIVEIRA, T. M. F. S.; SANTA ROSA, I. C. A. Babesiose canina: uma visão dos clínicos veterinários de Minas Gerais. Clínica Veterinária, ano 8, n. 41, p. 60-68, 2002.

INSTITUTO BRASILEIRO DE GEOGRAFIA E ESTATÍSTICA - IBGE. Censo Populacional de Minas Gerais. Rio de Janeiro: IBGE, 2000.

MADRUGA, C. R.; ARAÚJO, F. R.; SOARES, C. O. Imunodiagnóstico em medicina veterinária. Campo Grande: Embrapa Gado de Corte, 2001. 360 p.

MARTINS, C. S.; VIANA, J. A. Toxoplasmose: o que todo profissional de saúde deve saber. Clínica Veterinária, ano 3, n. 15, p. 33-37, 1998.

McAlLISTER, M. M. et al. Dogs are definitive hosts of Neospora caninum. International Journal for Parasitology, v. 28, n. 9 , p. $1473-1478,1998$.

MINEO, T. W. P. et al. Detection of IgG antibodies to Neospora caninum and Toxoplasma gondii in dogs examined in a veterinary hospital from Brazil. Veterinary Parasitology, v. 98, n. 4, p. 239-245, 2001.

OLIVEIRA, T. M. F. S. et al. A study of cross-reactivity in serum samples from dogs positive for Leishmania sp., Babesia canis and Ehrlichia canis in enzyme linked immunosorbent assay and indirect fluorescent antibody test. Revista Brasileira de Parasitologia Veterinária, v. 17, n. 1, p. 7-11, 2008.

PASSOS, L. M. F. et al. First molecular detection of Babesia vogeli in dogs from Brazil. Veterinary Parasitoloy, v. 127, n. 1, p. 81-85, 2005.

RIBEIRO, M. F. B. et al. Freqüência de anticorpos fluorescentes antiBabesia canis em cáes de Belo Horizonte, Minas Gerais. Arquivo Brasileiro Medicina Veterinária Zootecnia, v. 42, n. 6, p. 511-517, 1990.

SANTA-ROSA, I. C. A.; OLIVEIRA, I. C. S. Leishmaniose visceral: breve revisão sobre uma zoonose reemergente. Clínica Veterinária, ano 2, n. 11, p. 24-28, 1997.

SILVA, E. S. et al. Visceral Leishmaniasis in the Metropolitan Region of Belo Horizonte, State of Minas Gerais, Brazil. Memórias do Instituto Oswaldo Cruz, v. 96, n. 3, p. 285-291, 2001.

SILVA, D. O. et al. Evaluation of serological tests for the diagnosis of Neospora caninum infection in dogs: optimization of cut off titers and inhibition studies of cross-reactivity with Toxoplasma gondii. Veterinary Parasitology, v. 143, n. 3/4, p. 234-244, 2007.

SOUZA, S. L. P. et al. Occurrence of Toxoplasma gondii antibodies in sera from dogs of the urban and rural areas from Brazil. Revista Brasileira Parasitologia Veterinária, v. 12, n. 1, p. 1-3, 2003.

TRAPP, S. M. et al. Seroepidemiology of canine babesiosis and ehrlichiosis in a hospital population. Veterinary Parasitology, v. 140, n. 3/4, p. 223-230, 2006. 